\title{
O TUBO DE SILICONE COMO DRENO TORÁCICO EM EQÜINOS
}

\author{
THE SILICON TUBE WHEN USED AS A THORACIC DRAIN IN HORSES
}

\author{
Raquel Yvonne Arantes Baccarin ${ }^{1}$ Wilson Roberto Fernandes ${ }^{1}$ \\ Luis Cláudio Lopes Correia da Silva ${ }^{2}$ Manoel Eduardo Garcia Verenger ${ }^{3}$
}

RESUMO

O tórax agudo possui ocorrência comum em eqüinos, e é responsável por alta mortalidade. Diante disso, o aprimoramento dos meios de tratamento certamente contribuira para o maior índice de sobrevivência desses animais. Para tanto, este estudo teve a finalidade de avaliar: a complacência, capacidade de drenagem e a radiopacidade de tubo de silicone quando utilizado como dreno torácico em eqüinos $e$, as possíveis alterações causadas nas variáveis fisiológicas, no hemograma e no líquido pleural. O tubo de silicone foi introduzido na cavidade pleural de 10 eqüinos hígidos através de trocarte, mediante sedação dos animais e anestesia local. Após introdução e posicionamento, o tubo foi conectado a equipo de infusão e tampado por torneira de três vias. Avalioaram-se as variáveis fisiológicas dos animais, analisaram-se o hemograma, o fibrinogênio plasmático e o líquido pleural durante 15 dias. Os dados obtidos foram confrontados estatisticamente pela análise de variância. Concluiu-se que o tubo de silicone permite drenagem satisfatória; mantém sua consistência inalterada na presença do líquido pleural; é radiopaco ao exame radiográfico e é passível de alterar sua complacência na presença de vácuo.

Palavras-chave: eqüinos, dreno torácico, líquido pleural, silicone.

\section{SUMMARY}

The acute thorax syndrome is common in horses and has a high mortality rate. The development of more efficient treatment regimens will certainly account for an increased number of successful outcomes. The purpose of this research was to evaluate the silicon tube's complacency, draining ability and radiopacity when used as a thoracic drain in horses. Changes in physiologic parameters, blood cell count and pleural fluid were also investigated. Ten horses of different breeds, body weight and age were used and the silicon tube was placed in the pleural cavity by means of a trocar, with the horse under sedation and local anesthesia. Following introduction and placement in the ventral portion of the cavity, the tube was connected to an intravenous set and closed with a triple valve. Vital functions were monitored and blood cell count, plasmatic fibrinogen and pleural fluid were analysed. Data were evaluated by statistical multivariate analysis. Conclusions were: the silicon tube has good draining ability and maintains its consistency in contact with the pleural fluid; tube complacency can be affected; the tube has good radiopacity.

Key words: equine, thoracic drain, pleural fluid, silicon.

\section{INTRODUÇÃO}

A exemplo do que ocorre no abdômen, a cavidade torácica também pode ser sede de afecções que comprometem as funções vitais dos eqüinos. Nessas situações, configura-se o que se designa, genericamente, tórax agudo. As causas mais freqüentes de tórax agudo incluem traumatismos e afecções congênitas, degenerativas, neoplásicas ou infecciosas.

No tratamento direcionado para remoção de conteúdos do espaço pleural no tórax agudo, tanto em humanos como em eqüinos, são descritas várias técnicas. A escolha de uma delas, assim como do momento exato de sua utilização, são fatores de discussão entre autores. Apesar de a maioria deles concordar quanto à utilização da drenagem torácica, resta ainda a controvérsia quanto ao tipo de dreno torácico a ser empregado.

\footnotetext{
${ }^{1}$ Médico Veterinário, Professor Doutor do Departamento de Clínica Médica, Faculdade de Medicina Veterinária (FMVZ), Universidade de São Paulo (USP). Av.: Professor Orlando Marques de Paiva, 87, Cidade Universitária, Butantã, 05508-000, SãoPaulo, SP.E-mail: baccarin@usp.br. Autor para correspondência.

${ }^{2}$ Médico Veterinário, Professor Doutor do Departamento de Cirurgia, FMVZ, USP.

${ }^{3}$ Médico Veterinário da Universidade de Guarulhos - SP.
} 
Qualquer inclusão de corpos estranhos, mesmo que para fins terapêuticos, quase sempre induz reação. Os equipamentos utilizados são escolhidos na expectativa de não produzirem transtornos maiores que benefícios. Além de fabricados com materiais pouco reativos e esterilizados, devem ser colocados em situações que os tornem úteis, através de vias de acesso estudadas de modo a não danificar as estruturas orgânicas (MARQUES, 1992a). O dreno torácico deve ser visível ao exame radiográfico e ser suficientemente macio para permitir curvas; porém, deve possuir parede com espessura adequada para não colabar o seu lúmen (LAWRENCE, 1983)

Para a drenagem pleural, dois tipos de dreno podem ser utilizados: os tubulares multiperfurados e os drenos com furos em uma expansão distal. Os drenos tubulares multiperfurados podem se constituirem de materiais com características de borracha, plástico ou silicone. Os drenos com furos apenas em sua expansão distal ou "cabeça" (Pezzer ou Malecot) constituem-se de materiais com características de borracha (PERFEITO, 1995).

O dreno pleural mais utilizado em humanos é o tubular (PERFEITO, 1995). Em trabalho com 328 cirurgias torácicas, realizado por MUNNEL \& THOMAS (1975), foram estudadas as características do dreno torácico ideal. Deu-se preferência aos catéteres de plástico claros, radiopacos e multiperfurados, com diâmetro de 9,3 a $11,9 \mathrm{~mm}$ para adultos e 5,3 a $7,9 \mathrm{~mm}$ para crianças e adultos com pneumotórax. Em eqüinos, para toracocenteses intermitentes, CHAFFIN (1998) recomendou drenos torácicos comerciais pequenos de 4,0 a $6,6 \mathrm{~mm}$, e para drenagem torácica, drenos de 7,9 a $10,6 \mathrm{~mm}$, com trocarte removível. SCOTT II \& MANSMANN (1990) recomendaram drenos torácicos comerciais de tamanhos 4,0 a $6,6 \mathrm{~mm}$ para processos iniciais, quando o líquido pleural apresentava-se com baixa viscosidade.

O catéter de Foley, usado como dreno torácico, tem a desvantagem de possuir lúmen relativamente estreito e normalmente não ser radiopaco. Porém, tem a vantagem de poder ser melhor fixado dentro da cavidade pleural através de balão, dificultando a remoção acidental (LAWRENCE, 1983).

Entre as desvantagens dos drenos com furos na sua expansão distal, FILOMENO (1992) destacou que orifícios pequenos, na dependência da viscosidade do exsudato, facilitam a obstrução, mesmo quando a expansão distal é cortada, pois permanece um único orifício. $\mathrm{O}$ mesmo autor referiu-se também às paredes muito espessas, levando a um lúmen estreito de drenagem, e ao fato de o material (látex) ser excessivamente mole, permitindo estenoses por irregularidades do trajeto, além de não ser radiopaco.

A grande vantagem do uso de tubos de silicone é sua durabilidade, que é superior à do látex, estando, em função disso, indicado em afecções que requerem drenagem prolongada. Esse material ainda apresenta a vantagem de não amolecer quando em exposição prolongada a fluidos orgânicos, como acontece com o látex. Entretanto, há relatos de que os tubos de silicone potencializaram infecções quando utilizados para drenar a cavidade abdominal (JANN \& STECKEL, 1990).

A drenagem pleural não é isenta de riscos. Nos casos ordinários, pode-se ferir o feixe vasculonervoso intercostal e o parênquima pulmonar (LAVERTY et al., 1996), sendo que essa última lesão é mais provável quando existem sinéquias entre as pleuras visceral e parietal (MARQUES, 1992b). Além disso, esse autor também citou como complicações a contaminação da cavidade, a produção de empiema e a formação de pneumotórax.

A obstrução dos drenos ocorre freqüentemente em decorrência da presença de fibrina e/ou coágulos (FILOMENO, 1992), o que, segundo SCHOTT II \& MANSMANN (1990), pode ser agravado pela sucção freqüente, levando ao tamponamento do dreno até mesmo pelo tecido pulmonar.

Para CHAFFIN (1998), os drenos torácicos em eqüinos permitem a drenagem freqüente e contínua da cavidade pleural e normalmente não resultam em complicações. Porém, quando estas ocorrem, as mais comuns são: edema local, infecção subcutânea e pneumotórax, podendo ser facilmente resolvidas se rapidamente reconhecidas e tratadas.

Nesse contexto, este estudo teve a finalidade de avaliar a complacência, a capacidade de drenagem e a radiopacidade de tubo de silicone utilizado como dreno torácico em eqüinos. Concomitantemente, objetivou-se verificar possíveis alterações das variáveis fisiológicas, hemograma e líquido pleural, decorrentes da permanência desse dreno na cavidade torácica dos eqüinos.

\section{MATERIAL E MÉTODOS}

Foram utilizados 10 eqüinos hígidos, nove machos e uma fêmea, sem raça definida, com idade variando entre sete e 19 anos e peso entre 350 e $491 \mathrm{~kg}$. Os animais não apresentavam histórico de intervenção cirúrgica torácica e foram considerados aptos para utilização após exame físico, ultra- 
sonografia torácica, análise do hemograma e da concentração de fibrinogênio plasmático.

Após 12 horas de jejum, com o paciente em estação, realizou-se tricotomia no gradil costal direito, limpeza de pele e anti-sepsia. Administrouse romifidina ${ }^{\mathrm{a}}$ na dose de $0,08 \mathrm{mg} / \mathrm{kg}$ pela via intravenosa (i.v.), associada à infiltração de 200 a $400 \mathrm{mg}$ de lidocaína ${ }^{\mathrm{b}}$ no tecido subcutâneo e musculatura intercostal no local pré-estabelecido para a colocação do dreno. Decorridos 10 minutos, foi administrado butorfanol ${ }^{\mathrm{c}}$ na dose de $0,05 \mathrm{mg} / \mathrm{kg}$ i.v.

O local para colocação do dreno torácico foi o sétimo ou oitavo espaço intercostal (EIC) direito, aproximadamente $20 \mathrm{~cm}$ acima da linha horizontal imaginária que passa pelo olécrano. Após incisão vertical de $2,5 \mathrm{~cm}$ na pele e no tecido subcutâneo, cranialmente a oitava ou nona costela, realizaram-se a dissecação da musculatura intercostal e a perfuração da pleura parietal com auxílio de pinça hemostática reta kelly, evitando-se o plexo intercostal que percorre a borda caudal das costelas. Tal manobra permitiu a entrada de ar na cavidade pleural. Após a retirada da pinça, introduziu-se o trocarte de $12 \mathrm{~mm}$ de diâmetro. Este foi direcionado ventralmente, e o tubo de silicone ${ }^{\mathrm{d}}$, umedecido com solução de cloreto de sódio a $0,9 \%$, foi passado pelo interior da cânula do trocarte, margeando a parede torácica até atingir a região ventral. A cânula foi então retirada e o tubo foi conectado a um equipo cortado, que por sua vez estava conectado a uma torneira de três vias.

Para esvaziamento de ar da cavidade pleural, utilizou-se um aspirador cirúrgico ${ }^{\mathrm{e}}$. Uma vez instituído vácuo na cavidade pleural, sugerido através de alteração sonora do aspirador e colabamento do tubo de silicone, a torneira foi fechada. A pele foi suturada em pontos simples separados com fio de náilon 2.0, mantendo apenas o espaço necessário para a passagem do tubo, o qual foi fixado durante 10 dias através de bandagens ao redor do tórax.

Administrou-se penicilina benzatina ${ }^{\mathrm{f}}$ na dose de $20000 \mathrm{UI} / \mathrm{kg}$ por via intramuscular (i.m.), a cada 48 horas, durante seis dias. Os curativos da ferida cirúrgica foram diários, com solução aquosa de polivinilpirrolidona-iodo ${ }^{\mathrm{g}}$. $\mathrm{O}$ exame radiográfico do tórax de cada animal foi realizado 24 horas após a colocação do dreno torácico, para verificação da radiopacidade do tubo de silicone (Figura 1).

A avaliação pós-operatória constou de mensuração das freqüências cardíaca e respiratória durante um minuto, uma vez ao dia, durante 15 dias. Também foram observados o tipo e a intensidade dos movimentos respiratórios, bem como realizadas as auscultações pulmonares. A temperatura retal foi medida duas vezes ao dia, durante 15 dias, considerando-se a média do dia para efeitos de cálculo. No exame físico também foram incluídos tempo de perfusão capilar (TPC), avaliações das mucosas ocular e oral, movimentos digestivos, freqüência de defecação e micção, avaliação do apetite, palpação profunda dos espaços intercostais para averiguar presença de dor e, finalmente, avaliação da ferida cirúrgica.

Foram colhidas amostras de sangue, através de venopunção jugular esquerda, para hemograma e concentração de fibrinogênio plasmático. As coleta foram realizadas 24 horas antes do ato cirúrgico e um, dois, cinco, sete, 10 e 15 dias após a colocação do dreno. Já as amostras de líquido pleural $(10 \mathrm{~m} \ell)$ foram colhidas através do dreno torácico e armazenadas em frascos contendo EDTA, sendo em seguida encaminhadas para análise, nos dias um, dois, cinco, sete e 10 após a colocação do dreno.

Os dados obtidos das variáveis físicas, hematológicas e do líquido pleural que apresentaram normalidade foram analisadas comparando-se os tempos de coleta após colocação do dreno, utilizando-se o teste "F" da análise de variância, considerando significativo quando $\mathrm{p}<0,05$. As variáveis hematológicas: monócito, basófilo e eosinófilo do sangue e leucócitos do líquido pleural foram transformadas em $\log _{(x+1)}$, para obtenção de normalidade.

Nos casos em que a estatística resultou significativa $(p<0,05)$, foram efetuados contrastes entre médias pelo teste de TUKEY pela diferença mínima significativa (dms) (SAMPAIO, 1998).

\section{RESULTADOS}

A colocação do tubo de silicone foi facilitada tanto pela umidificação com solução fisiológica $0,9 \%$, quanto pelo direcionamento ventral dado pela cânula do trocarte. Somente em um eqüino houve resistência na passagem desse, por entre o pulmão e a parede torácica, ocasionando dúvidas quanto a posição da extremidade distal do dreno e ocorrendo hemorragia na cavidade torácica. Os exames radiográficos, comprovaram a radiopacidade do tubo de silicone quando utilizado como dreno torácico.

As amostras de líquido pleural foram facilmente colhidas através do dreno, mesmo quando continham fibrina e coágulos, mostrando adequada drenagem. Contudo, o acoplamento deste ao equipo e torneira de três vias impediu a passagem desses componentes, entupindo ora o equipo, ora a torneira 


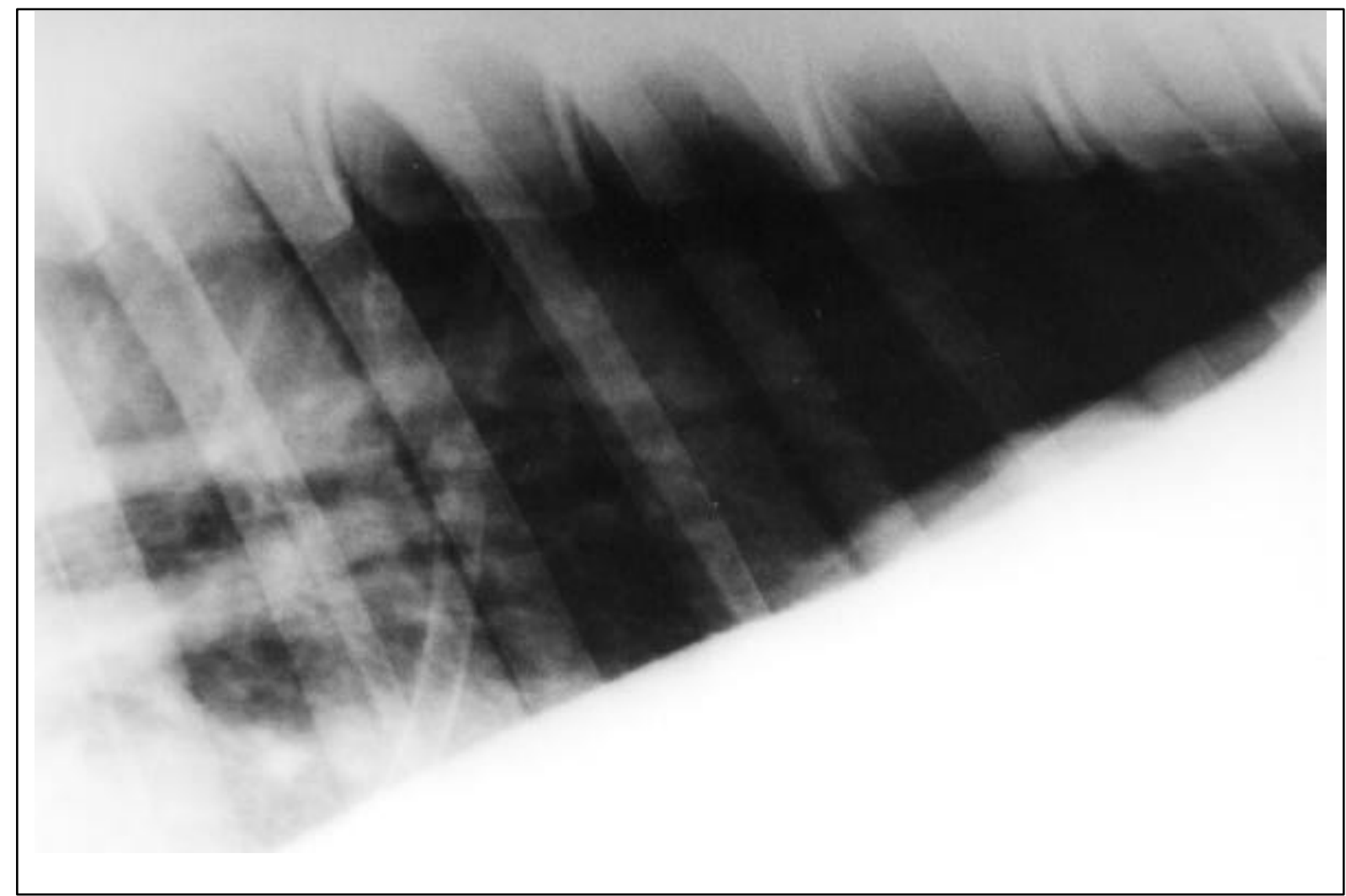

Figura 1 - Imagem radiográfica monstrando a radiopacidade do dreno torácico de silicone, acoplado a equipo de transfusão, situado no oitavo espaço intercostal direito.

de três vias, fazendo com que houvesse a necessidade de trocá-los em três animais. Apesar disso, a torneira de três vias permitiu a coleta do líquido pleural sem que houvesse entrada de ar na cavidade. Ao final de cada drenagem, o tubo de silicone colabou com a pressão de sucção, sugerindo o esgotamento de líquido. Também foi observado colabamento nos casos de tamponamento temporário do mesmo por coágulo.

No período pós-operatório, os animais se mostraram ativos, sem relutância à movimentação, sem dor à palpação profunda dos espaços intercostais, alimentando-se normalmente e com boa expansão da cavidade torácica durante a inspiração. Não foram observadas alterações na freqüência de defecação ou micção, nos movimentos digestivos, no TPC, ou na coloração e aspecto das mucosas ocular e oral.

Os valores resultantes da mensuração da freqüência cardíaca, freqüência respiratória e temperatura retal nos diferentes dias não mostraram diferença significativa quando comparados com o valor controle, apesar de dois animais apresentarem dispnéia durante o pós-operatório imediato. Em um dos equiinos, a dispnéia decorreu do desenvolvimento de pneumotórax; já no outro, a dispnéia originou-se pela dor decorrente da presença do dreno na cavidade pleural, solucionada pela retração de $5 \mathrm{~cm}$ do dreno. Quanto à auscultação, não foram notadas alterações de sons respiratórios ou de ritmo nem da intensidade de sons cardíacos nas avaliações pós-operatórias.

Os valores do eritrograma durante o período pós-operatório não mostraram diferenças significativas quando comparados aos valores controles. Houve aumentos significativos nos valores de leucócitos e neutrófilos $(\mathrm{p}<0,05)$ após 24 horas da colocação do dreno torácico e aumento no valor de basófilos 24 e 48 horas $(\mathrm{p}<0,05)$, quando comparados ao valor controle. Já os valores médios de eosinófilos, linfócitos e monócitos não mostraram diferença significativa entre os tempos analisados. Notou-se aumento progressivo, apesar de não significativo, nas concentrações de fibrinogênio. Somente houve aumento $(p<0,05)$ na concentração média de fibrinogênio no décimo dia de pósoperatório quando comparado ao valor controle.

Em relação à análise do líquido pleural, não foram observadas diferenças $(p>0,05)$ nos 
valores de $\mathrm{pH}$, densidade e proteína, porém, observou-se aumento significativo $(p<0,05)$ de leucócitos no sétimo dia de pós-operatório quando comparado com os valores do segundo e décimo dias. $\mathrm{Na}$ avaliação citológica do líquido pleural, 24 horas após a colocação do dreno, notou-se predominância de neutrófilos (80-98\%) com alguns macrófagos (1-10\%) e raros linfócitos (1-2\%). Em sete animais, observaram-se hemácias no líquido pleural, e somente em um animal havia eosinófilos.

$$
\text { Os neutrófilos permaneceram }
$$

predominantes até o décimo dia, sendo que, a partir de 48 horas, $5 \%$ desses já estavam degenerados e, no décimo dia, $87 \%$ encontravam-se degenerados. O número de macrófagos aumentou no quinto dia de pós-operatório, permanecendo estável até o décimo dia. Também no quinto dia notou-se a presença de leucofagocitose e eritrofagocitose. Os linfócitos permaneceram raros, assim como os eosinófilos.

Notou-se presença de hemácias na maioria dos esfregaços. A presença de bactérias foi observada nos esfregaços de dois animais, 48 horas após a colocação do dreno torácico, de outros dois animais no quinto dia de pós-operatório, de três animais no sétimo dia de pós-operatório, e de seis animais no décimo dia de pós-operatório.

\section{DISCUSSÃO}

Observou-se que a boa umidificação do tubo de silicone é importante para que ocorra melhor deslizamento quando da colocação, não acarretando em lesões pleurais ou dos feixes vasculonervosos. A falha de umidificação provavelmente ocorreu em um eqüino, fazendo com que houvesse várias tentativas de direcionamento do tubo entre o pulmão e a parede torácica, ocasionando hemorragia na cavidade, o que, segundo MARQUES (1992b) e LAVERTY $\boldsymbol{e}$ al. (1996), é um dos acidentes passíveis de ocorrer durante a colocação de dreno torácico.

Igualmente ao que acontece em humanos, o dreno de melhor utilização em eqüinos é o tubular (SCHOTT II \& MANSMANN, 1990; PERFEITO,1995; CHAFFIN, 1998), variando somente o calibre de acordo com o tamanho do paciente. Neste trabalho, também optou-se pelo dreno torácico tubular, porém de calibre $11,5 \mathrm{~mm}$, maior do que o recomendado por SCHOTT II e MANSMANN (1990) e CHAFFIN (1998) para eqüinos, para ficilitar a drenagem de fibrina e coágulos caso fossem formados. Optou-se também por utilizar o silicone que, igualmente ao observado por JANN \& STECKEL (1990), não alterou sua consistência, mesmo permanecendo em contato com o líquido pleural.
O tubo de silicone permitiu adequada drenagem, não sofrendo dobras por irregularidades do trajeto, diferente do que ocorre com os drenos de borracha, conforme relatado por FILOMENO (1992).

Apesar da formação de fibrina e coágulos, esses não eram em quantidade suficiente para causar impedimento da drenagem. Durante o experimento, ocorreram obstruções somente no trajeto do equipo e torneira de três vias, indicando necessidade de melhora do sistema que acopla o dreno ao equipamento de sucção. Essa sucção, utilizada para aspiração do líquido pleural, predispôs ao tamponamento do tubo pelo pulmão, como relatado por SCOTT II \& MANSMANN (1990).

Através dos exames radiográficos, pôdese comprovar a radiopacidade do tubo de silicone, a qual, segundo MUNNEL \& THOMAS (1975) e LAWRENCE (1983), é uma das características ideais do dreno torácico.

$\mathrm{O}$ aumento do número médio de leucócitos deveu-se principalmente ao aumento absoluto do número de neutrófilos, observado 24 horas após à colocação do dreno. Porém, não foi possível caracterizar leucocitose, provavelmente devido a baixa severidade da inflamação e contaminação do líquido pleural. $\mathrm{O}$ aumento do número de basófilos 24 horas após a colocação do tubo deveu-se ao início do processo inflamatório, uma vez que essas células secretam histamina e fator anticoagulante antitrombínico, possuindo importância no combate às infecções (BIRGEL, 1982).

Notou-se aumento progressivo, apesar de não significativo, nas concentrações de fibrinogênio até o décimo dia de pós-operatório, indicando processo inflamatório crônico resultante da permanência do dreno. Cinco dias após a retirada do dreno, observou-se tendência à diminuição dessas concentrações, caracterizando a natureza irritativa dos corpos estranhos em cavidades orgânicas.

Houve contaminação bacteriana do líquido pleural, como observado nos exames de dois animais 48 horas após a colocação do dreno, de dois animais no quinto dia, de três animais no sétimo dia, e de seis animais no décimo dia.Isso sugeriu que a permanência do dreno permite a contaminação por manter contato da cavidade pleural com o meio externo. Logo, é lícito afirmar que a contaminação e a formação de empiema pleural são complicações ligadas à drenagem pleural, podendo-se, então, concordar com MARQUES (1992b) que as inclusões de corpos estranhos na cavidade pleural podem causar processos supurativos. Porém, não foi possível confirmar que o tubo de silicone 
potencializa a infecção, como relatado por JANN e STECKEL (1990).

No decorrer do experimento, observaramse hemácias nas avaliações citológicas do líquido pleural nos diferentes tempos. Acredita-se que a manipulação do dreno durante as coletas, juntamente com o fato de este não estar fixado na pele ou musculatura, ocasionaram hemorragia, provinda dos músculos intercostais, como relataram PARRY (1992) e CHAFFIN (1994).

Pelos valores de normalidade dados por PARRY (1992), a concentração protéica do líquido pleural, no decorrer do experimento, permaneceu aumentada. Deve-se observar que há um aumento de fibrinogênio plasmático, apesar de não significativo, já a partir de 24 horas, culminando no décimo dia de pós-operatório. Os valores de leucócitos no líquido pleural, no decorrer do experimento, apresentaram médias dentro da faixa de normalidade, segundo os dados reportados por PARRY (1992) e CHAFFIN (1994), exceto no sétimo dia de pós-operatório, em que a média do número de células foi de $21590 / \mu \ell$. Esse valor decorreu da contaminação bacteriana do líquido pleural de um eqüino, observada na avaliação citológica, o que fez com que a média do número de leucócitos ficasse acima do normal.

Durante o decorrer do experimento, a distribuição celular no líquido pleural não se alterou, mantendo-se igual a de líquidos normais. Porém, observou-se alteração na quantidade e morfologia das células. Tanto neutrófilos quanto macrófagos apresentaram atividades de eritrofagocitose e leucofagocitose, as quais, segundo PARRY (1992), não são estruturas compatíveis com líquido pleural normal. Ainda foi observado grande número de neutrófilos degenerados, o que, segundo BENNETT (1986), quando na presença de elevado volume de líquido pleural, indica pleurisia difusa, e quando associado à pequena quantidade, indica abscesso pleural. Apesar dessa colocação, neste experimento, em que se observou pequena quantidade de líquido pleural, não foi encontrado abscesso pleural, mas sim uma pleurite focal.

Segundo a classificação utilizada por PARRY (1992) e CHAFFIN (1994), a maioria dos líquidos pleurais colhidos foram classificados como transudato modificado, pois possuíam baixa contagem de células nucleadas $(<10000 / \mu \ell)$, mas moderada concentração protéica $(4,3$ a $4,9 \mathrm{~g} / \mathrm{d} \ell)$. A exceção ocorreu no sétimo dia, quando o líquido pleural foi classificado em exsudato, pois a média possuía alta contagem de células nucleadas $(>10000 / \mu \ell)$ e elevada concentração protéica $(4,9 \mathrm{~g} / \mathrm{d} \ell)$. Isso foi decorrente da contaminação bacteriana do líquido pleural de um eqüino, que acabou ocasionando o aumentou dessas médias.

\section{CONCLUSÕES}

Considerando as observações ao longo do experimento, pode-se concluir que a presença do tubo de silicone na cavidade pleural de eqüinos causa inflamação discreta e possibilita a contaminação bacteriana. Entretanto, o tubo de silicone permite drenagem adequada; mantém sua consistência inalterada na presença do líquido pleural; é radiopaco no exame radiográfico e é passível de alterar sua complacência somente na presença de vácuo.

\section{FONTES DE AQUISIÇÃO}

${ }^{\text {a }}$ Sedivet - Boehringer Ingelheim

${ }^{\mathrm{b}}$ Lidol - Hipolabor

${ }^{\mathrm{c}}$ Torbugesic - Ford Dodge

${ }^{\mathrm{d}}$ Tubo de silicone de 8 x 11,5mm de diâmetro-modelo 205 c-100

- Perfitécnica

${ }^{\mathrm{e}}$ Aspirador NS, modelo MA-520 - Aspira Max

${ }^{\mathrm{f}}$ Pentabiótico veterinário reforçado - Ford Dodge

${ }^{\mathrm{g}}$ HI-ODIN tópico - Halex Istar

\section{REFERÊNCIAS BIBLIOGRÁFICAS}

BENNETT, D.G. Evaluation of pleural fluid in the diagnosis of thoracic disease in the horse. Journal of the American Veterinary Medical Association, v.188, n.8, p.814-815, 1986.

BIRGEL, E.H. Hematologia clínica veterinária. In: BIRGEL, E.H., BENESI, F.J. Patologia clínica veterinária. São Paulo : Sociedade Paulista de Medicina Veterinária, 1982. p.2-69.

CHAFFIN, M.K. Diagnostic assessment of pleural effusion in horses. Compendium on Continuing Education for the Practicing Veterinarian, v.16, n.8, p.1035-1039, 1994.

CHAFFIN, M.K. Thoracocentesis and pleural drainage in horses Equine Veterinary Education, v.10, n.2, p.106-108, 1998.

FILOMENO, L.T.B. Empiema pleural. In: MORAES, I.N., MELLO, J.B., NAHAS, P. Residente de cirurgia. São Paulo : Roca, 1992. p 384-389.

JANN, H.W., STECKEL, R.R. The use of drains in equine surgery. Equine Practice, v.12, n.9, p. 6-13, 1990.

LAVERTY, S., LAVOIE, J.P., PASCOE, J.R., et al. Penetrating wounds of the thorax in 15 horses. Equine Veterinary Journal, v.28, n.3, p.220-224, 1996.

LAWRENCE, G.H. Problems of the pleural space. Philadelphia : Saunders, 1983. Closed chest tube drainage for pleural space problems: p.13-24.

MARQUES, E. Tórax agudo - estratégia e tática em cirurgia torácica de urgência. São Paulo : Sarvier, 1992a. Tórax agudo traumático: p.77-149. 
MARQUES, E. Tórax agudo - estratégia e tática em cirurgia torácica de urgência. São Paulo: Sarvier, 1992b. Tórax agudo iatrogênico: p.317-319.

MUNNELL, E.R., THOMAS, E.K. Current concepts in thoracic drainage systems. Annals Thoracic Surgery, v.19, n.3, p.261-263, 1975 .

PARRY, B.W. Pleural fluid. In: COWELL, R.L., TYLER, R.D Cytology and hematology of the horse. Goleta: American Veterinary, 1992. p.107-120.
PERFEITO, J.A.J. Drenagem pleural. In: FRISOLI, A.; LOPES, A.C.; AMARAL, J.L.G., et al. Emergências: Manual de diagnóstico e tratamento. São Paulo : Sarvier, 1995. p.583-587.

SAMPAIO, I.B.M. Estatística aplicada à experimentação animal. Belo Horizonte : Fundação de pesquisa e ensino em Medicina Veterinária e Zootecnia, 1998. 221p.

SCHOTT II, H.C., MANSMANN, R.A. Thoracic drainage in horses. Compendium on Continuing Education for the Practicing Veterinarian, v.12, n.2, p.251-261, 1990. 